\title{
OPTIMIZATION OF SPRAY-DRYING PROCESS FOR CONCENTRATED ORANGE JUICE
}

\author{
J.A. Pino*, Y. Aragüez-Fortes and M. Bringas-Lantigua \\ Food Industry Research Institute, Carretera al Guatao km 3 1⁄2, Havana, POB 19200. Cuba
}

(Received: 23 November 2017; accepted: 14 March 2018)

\begin{abstract}
Response surface methodology was used to optimize spray-drying process for concentrated orange juice. Independent variables were: inlet air temperature $\left(130-170{ }^{\circ} \mathrm{C}\right)$ and maltodextrin $12 \mathrm{DE}$ content $(60-75 \%$ wet basis (wb)). Responses variables were powder yield, moisture, and ascorbic acid retention. Moisture content was negatively affected by inlet air temperature, while ascorbic acid retention was directly related. Powder yield and ascorbic acid retention increased with the rise in maltodextrin content, while moisture content was negatively affected by maltodextrin content. Multiple response optimisation indicated that an inlet air temperature of $155{ }^{\circ} \mathrm{C}$ and maltodextrin content of $74 \% \mathrm{wb}$ were predicted to provide $77 \%$ powder yield, $3.7 \% \mathrm{wb}$ moisture content, and $89 \%$ ascorbic acid retention.
\end{abstract}

Keywords: concentrated orange juice, spray drying, optimization, ascorbic acid retention

Orange juice is one of the major traded products throughout the world, and the most widely consumed fruit juice. This can be attributed to its flavour and colour, as well as it is a great source of vitamin C and bioactive compounds (CESAR et al., 2010; O'NEIL et al., 2011). However, orange juice presents a high amount of water, which increases its transport cost and it should be stored at refrigeration temperature. Spray drying can be applied to turn the orange juice into powder that has longer shelf life and is readily available (KRISHNAIAH et al., 2014). Ideally, spray-dried orange juice powder should have instant properties, can be served as a source of vitamin $\mathrm{C}$ and used as functional ingredient rich in bioactive compounds in dried food products.

Dehydration by spray drying is used extensively in the food industry for a wide range of products (MURUGESAN \& ORSAT, 2012). However, a major problem during spray drying of sugar-rich foods, such as fruit juices, is their thermoplastic behaviour. The chemical composition of fruit juices comprises components of low glass transition temperature $\left(\mathrm{T}_{\mathrm{g}}\right)$, mainly monosaccharides and organic acids, and during drying they may either remain as syrup or stick on the dryer chamber wall (Phisut, 2012; Verma \& Singh, 2013). This might lead to low product yields and operating problems, which can be minimized by the addition of high molecular weight additives before atomizing to prevent stickiness of product by increasing the $\mathrm{T}_{\mathrm{g}}$ during the process and/or optimizing the drying parameters (MuZAFFAR et al., 2015). Among these additives, maltodextrin (MD) has the advantage to increase $T_{g}$ and improve the sweetness of the product (PHISUT, 2012). As additive addition alters the product's sensory properties, it may be desirable to optimize the amount, keeping in view the free flowing nature of the product and higher fruit juice solids in the final product.

\footnotetext{
* To whom correspondence should be addressed. Phone: +53 72793956; e-mail: jpino@iiia.edu.cu
} 
There is considerable amount of work on spray drying of orange juice in the literature, mainly on lab-scale spray dryer (Chegini \& GHobadian, 2007; Shrestha et al., 2007; Chegini et al., 2008; Goula \& Adamopoulos, 2010; TAN et al., 2011; WANG et al., 2011; Islam et al., 2016) or rotary atomizer without optimization (CHEGINI \& GHOBADIAN, 2005). However, there is limited scientific literature concerning the optimization of spray-drying process of concentrated orange juice (COJ) in pilot and/or rotary atomizer spray dryer, which is required to allow reliable extrapolation of drying data over various operating conditions and product parameters. Based on the above reasons, this study was undertaken to investigate the influence of inlet air temperature and MD content, on the physicochemical properties during the spray drying of COJ and to determine the optimum drying conditions for the production process, by using response surface methodology.

\section{Materials and methods}

COJ was obtained from Cítricos Caribe S.A., Cuba. The basic composition of COJ was total soluble solids $62.7^{\circ} \mathrm{Brix}$, citric acid $4.2 \mathrm{~g} / 100 \mathrm{~g}$, and ascorbic acid $288 \mathrm{mg} / 100 \mathrm{~g}$. Maltodextrin 12DE (IMSA, Guadalajara, Mexico) with a moisture content of $4.0 \%$ wb was used as carrier agent. Taking into account the total soluble solids of COJ and MD, solids at ratios 1:1.5; 1:2.08, and 1:3.0 (COJ:MD) by weight were selected for spray drying after some preliminary experiments (results not shown). This means MD contents of 60,67.5, and 75\% wb. An essence was prepared from the deterpenated cold pressed orange oil with $64 \% \mathrm{wb}$ ethanol at a ratio of 1:0.07. This essence was added in a ratio of $10: 1 \mathrm{~m} / \mathrm{m}$ juice:essence to reinforce the flavour of the concentrated juice. This ratio was determined by sensory evaluation with consumer panellists. Tricalcium phosphate (Amfher Foods, Mexico D.F.) was used at $0.08 \%$ $\mathrm{wb}$ in the feed solution to prevent agglomeration of the powder (JAYA \& DAS, 2004). Ingredients were mixed using a mechanical stirrer at 800 r.p.m. for $15 \mathrm{~min}$ to obtain a uniform solution. A total of $3 \mathrm{~kg}$ of the feed solution was prepared with a final solids content of $30 \%$ wb for each spray drying run.

Spray drying of feed solutions was carried out in a pilot rotary atomizer Mobile Minor spray dryer (Niro Atomizer Ltd., Copenhagen, Denmark) under the following conditions: inlet air temperature: 130,150 , and $170{ }^{\circ} \mathrm{C}$; atomising disk speed: 30000 r.p.m., and outlet air temperature: $75 \pm 5^{\circ} \mathrm{C}$. The product was fed to the spray dryer at room temperature at a rate of $75-170 \mathrm{ml} \mathrm{min}{ }^{-1}$ : the rate was adjusted to keep the outlet air temperature at the desired value. These parameters were chosen on the basis of preliminary experiments, which yielded what appeared to be an acceptable spray dried powder. Each spray drying run was performed in duplicate, with the exception of four replicates of the central point. The orange juice powders were collected from the cyclone separator, packed in polythene bags, and stored in a desiccator at $20{ }^{\circ} \mathrm{C}$ before being submitted to triplicate analyses.

Powder yield was evaluated by the determination of the product recovery given by the percentual ratio between the total mass of product recovered by the mass of extract fed to the system (dry basis). Moisture content of powders ( $2 \mathrm{~g}$ ) was determined in an electronic moisture balance Sartorius mod. MA35 (Goettingen, Germany) instrument. Total ascorbic acid content was determined by titration with 2,6-dichlorophenol-indophenol according to a standard method (AOAC, 2006). The retention percentage of ascorbic acid content of orange juice powder was calculated by the formula: ascorbic acid content of orange juice powder 
$(\mathrm{mg} / 100 \mathrm{~g})$ after drying $\times$ 100/ascorbic acid content of COJ/MD mixture (mg/100 g) before drying.

Particle size and structure of the powder obtained with the optimized parameters were evaluated using a scanning electron microscopy 5130 SB (Tescam, Praga, Czech Republic). The sample was separately mounted on aluminium stubs using double scotch tape and sputter-coated with a thin layer of gold. Finally, the coated sample was transferred to the microscope, where it was observed at an acceleration potential of $10 \mathrm{kV}$. Images at $\times 2000$ magnification were obtained with the software associated with the equipment, and the average particle size $\mathrm{D}_{43}$ was calculated.

The acceptance of the powder obtained with the optimized parameters was evaluated in a sensory assay by 80 non-trained adults, using a non-structured scale. The samples were reconstituted to $12 \%$ solid content and were randomly served to the panellists in white cups. The panellists were instructed to indicate their preference for the sample.

A three-level factorial design was used to set up the tests for the spray drying process, considering two factors (independent variables): inlet air temperature and MD content, requiring 12 experimental runs. Powder yield, moisture content, and ascorbic acid retention were used as response variables. The final goal of response surface methodology is to determine the optimum conditions for the system or to determine a region in the total space of the factors, in which certain desirable conditions are satisfied (MonTGOMERY, 2013). Desirability is an objective function that ranges from zero outside of the limits to one at the goal. The numerical optimization finds a point (conditions) that maximizes the desirability function (response variables). For several responses and factors, all goals are combined into one desirability function. The analysis of variance, test for the lack of fit, determination of the regression coefficients, and the generation of three dimensional graphs were carried out using the software package Design-Expert ver. 8 (Statease Inc., Minneapolis, MN).

\section{Results and discussion}

Physicochemical properties of the orange juice powders produced at different inlet air temperatures and MD contents were evaluated. The average experimental results of these physicochemical properties are shown in Table 1. Table 2 shows the regression coefficients for the coded second order polynomial equation, the $F$ value, and the determination coefficients $\left(\mathrm{R}^{2}\right)$. Some non-significant terms were eliminated and the resulting equations were tested for adequacy and fitness by ANOVA. The fitted models gave satisfactory adjustment of the reduced response models used for describing the response variables as function of both evaluated factors.

Powder yield ranged from 34 to $80.6 \% \mathrm{wb}$ (Table 1). These results were similar to those found for $\sim 65-75 \% \mathrm{wb}$ in the spray drying of COJ with MD and an unknown protein (WANG et al., 2011), and 53.0-63.3\% wb using vacuum spray drying and MD in the same proportions (IsLAm et al., 2016). In general, powder yields of the present work were higher than the 18$35 \%$ wb reported previously (CHEGINI \& GHOBADIAN, 2007), 40-85\% wb using a spray dryer with cold walls chamber and maltodextrin in the same proportions (CHEGINI et al., 2008), and $31.2-65.6 \%$ wb using skim milk (RAO \& GUPTA, 2002). On the contrary, powder yields of the present work were lower than 86-95\% wb using dehumidified air and MD (Goula \& Adamopoulos, 2010). 
Table 1. Experimental data for response surface analysis of the effect of processing conditions on the quality of orange juice powder

\begin{tabular}{|c|c|c|c|c|}
\hline $\begin{array}{l}\text { Inlet air temperature } \\
\left({ }^{\circ} \mathrm{C}\right)\end{array}$ & $\begin{array}{c}\text { Maltodextrin } \\
(\% \mathrm{wb})\end{array}$ & $\begin{array}{c}\text { Powder yield } \\
(\% \mathrm{wb})\end{array}$ & Moisture $(\% \mathrm{wb})$ & $\begin{array}{l}\text { Ascorbic acid } \\
\text { retention }(\%) \\
\end{array}$ \\
\hline 130 & 60.0 & 51.0 & 4.69 & 73.2 \\
\hline 130 & 67.5 & 69.8 & 4.60 & 77.4 \\
\hline 130 & 75.0 & 70.9 & 4.01 & 83.1 \\
\hline 150 & 60.0 & 44.2 & 4.35 & 84.1 \\
\hline 150 & 67.5 & 66.5 & 4.35 & 89.5 \\
\hline 150 & 67.5 & 70.1 & 3.92 & 89.6 \\
\hline 150 & 67.5 & 67.2 & 3.96 & 87.3 \\
\hline 150 & 67.5 & 64.5 & 3.93 & 88.0 \\
\hline 150 & 75.0 & 80.6 & 3.86 & 89.0 \\
\hline 170 & 60.0 & 34.0 & 3.84 & 79.3 \\
\hline 170 & 67.5 & 69.1 & 3.87 & 81.7 \\
\hline 170 & 75.0 & 75.1 & 3.63 & 82.5 \\
\hline
\end{tabular}

wb: wet basis

Table 2. Coded regression coefficients for the physicochemical properties of orange juice powder

\begin{tabular}{lccc}
\hline Coefficient & Powder yield & Moisture & Ascorbic acid retention \\
\hline Intercept & 68.25 & 4.08 & 88.27 \\
$\mathrm{X}_{\mathrm{T}}$ & -2.25 & $-0.33 * * *$ & $1.63 *$ \\
$\mathrm{X}_{\mathrm{M}}$ & $16.23 * * *$ & $-0.23 * *$ & $3.00^{* * * *}$ \\
$\mathrm{X}_{\mathrm{T}}{ }^{2}$ & -1.14 & 0.07 & $-8.04 * * *$ \\
$\mathrm{X}_{\mathrm{M}}{ }^{2}$ & $-8.19 * *$ & -0.06 & -1.04 \\
$\mathrm{X}_{\mathrm{T}} \mathrm{X}_{\mathrm{M}}$ & $5.30^{*}$ & 0.12 & $-1.67 *$ \\
$\mathrm{R}^{2}$ & 0.965 & 0.852 & 0.972 \\
$\mathrm{~F}$ & $32.70 * * *$ & $6.93 *$ & $42.25 * * *$ \\
\hline
\end{tabular}

$\mathrm{X}_{\mathrm{T}}, \mathrm{X}_{\mathrm{M}}$ : coded inlet air temperature and maltodextrin content, respectively.

*: Significant at $\mathrm{P} \leq 0.05$; **: Significant at $\mathrm{P} \leq 0.01$; *** Significant at $\mathrm{P} \leq 0.001$.

Powder yield was significantly influenced by MD content (Table 2). The coefficients of the first order terms with coded variables indicated that yield increased with the rise in MD content. It is related to increasing $\mathrm{T}_{\mathrm{g}}$ values of the amorphous fractions in the mixtures that are rich in low $\mathrm{T}_{\mathrm{g}}$ components. This finding is congruent with those reported for the spraydrying of orange juice (Shrestha et al., 2007; Goula \& Adamopoulos, 2010; Islam et al., 2016).

Moisture content varied from 3.63 to $4.69 \% \mathrm{wb}$ (Table 1), which is similar to the results represented by other researchers (Shrestha et al., 2007; Goula \& Adamopoulos, 2010), but higher than 2.29-3.35\% wb using vacuum spray drying (IsLAm et al., 2016).

The linear effects of both independent variables on moisture content were significant and with a negative relationship (Table 3 ). When inlet air with high temperature was contacted with liquid feed, it led to greater efficiency of heat and mass transfer, and hence greater evaporation rate to evaporate moisture from the droplets (Goula \& AdAmopoulos, 2010). 
The increase in MD content also caused a significant decrease in powder moisture. This can be explained by the fact that the addition of coating material leads to higher amount of solids in the feed and less water to be evaporated. Analogous results were found in the spray drying of COJ (SHRESTHA et al., 2007; IsLAM et al., 2016) and other fruit juices (FAZAELI et al., 2012; Mishra et al., 2014; Movahned \& MonebBi, 2016). Nevertheless, in the spray drying of $\mathrm{COJ}$ an increase in moisture content was found with an increase in MD concentration (GouLA \& AdAmopoulos, 2010). This finding was attributed to the presence of larger MD molecules, which makes diffusion of water molecules difficult, but in this work the high MD content was employed for producing powder and because of this increasing carrier concentration resulted in an increase in moisture content.

Bearing in mind that ascorbic acid (vitamin C) is an important water-soluble and highly heat-sensitive substance; it is quite odd that its content is not often used as an indicator of heat damage during spray drying of orange juice. A goal of the present study was to retain higher amount of ascorbic acid in the powder. Ascorbic acid retention of the powders varied from 73.2 to $89.6 \%$ (Table 2), which were similar to $75.9-83.7 \%$ in the spray drying of sour orange juice (Cuevas-Glory et al., 2017), but higher than 64.9-71.0\% in the vacuum spray drying of COJ (IsLAm et al., 2016). In general, ascorbic acid retentions of the present work were also higher than those reported for the spray drying of other fruit juices (KAYA et al., 2010; PATIL et al., 2014).

According to Table 2, the linear and quadratic effects of inlet air temperature, the lineal effect of MD concentration, and their interaction on ascorbic acid retention were significant. The positive coefficient of the first order term showed that ascorbic acid retention of the orange juice powder increased significantly by increasing inlet air temperature, but the negative effect of the quadratic term was higher than the first order term, so there is a curvature in the contour plot, with maximal retention in the range $150-160{ }^{\circ} \mathrm{C}$ within the experimental ranges studied. Inlet air temperature is directly proportional to the microcapsule drying rate and the final water content. At low inlet air temperature, the low evaporation rate causes the formation of microcapsules with high density membranes, high water content, and slow evaporative rate, consequently causing an important loss of ascorbic acid. On the other hand, a high inlet air temperature causes an excessive evaporation resulting cracks in the membrane and inducing subsequent premature degradation of encapsulated ascorbic acid by contact with oxygen. Thus, the inlet air temperature is usually determined by the temperature, which can safely be used without damaging the product (GHARSALLAOUI et al., 2007). The pattern of the findings was similar to those found for other fruit juices (PATIL et al., 2014; Cuevas-Glory et al., 2017). Nevertheless, other studies reported an opposite effect (MoreIRA et al., 2010; SINGH et al., 2013), but in all cases higher inlet air temperatures were used. MD content significantly affects the ascorbic acid retention of orange juice powder. Increasing the amount of drying agent in the feed mixture produced an increase in ascorbic acid retention. This is probably due to the high encapsulation rate of excess MD present in the feed mixture, thereby preventing ascorbic acid from degradation. Indeed, similar results were reported, for example, during spray drying of acerola pomace extract (MoREIRA et al., 2010) and sour orange juice (Cuevas-Glory et al., 2017). However, the increase of MD solids has no effect of the ascorbic acid retention during the vacuum spray drying of COJ (IsLAm et al., 2016).

Numerical optimization was carried out for the process parameters of orange juice powder. The desired goals for each response were chosen to be as follows: to maximize powder yield, ascorbic acid retention, and to minimize moisture content. These response variables were selected as most important for the optimization. Beside this, three response 
variables give better freedom degrees for the numerical optimization. Figure 1 shows the response surface plot obtained for the optimization of the process parameters. The best response was obtained with an inlet air temperature of $155^{\circ} \mathrm{C}$ and $\mathrm{MD}$ content of $74 \% \mathrm{wb}$. Under such conditions, powder yield was estimated to be $77 \%$, moisture content $3.7 \% \mathrm{wb}$, ascorbic acid retention $89 \%$, $63 \mathrm{~s}$ solubility time, $0.5159 \mathrm{~g} \mathrm{~cm}^{-3}$ tapped density, and hygroscopicity $23.7 \mathrm{~g}$ of adsorbed moisture per $100 \mathrm{~g}$ of dry solids.

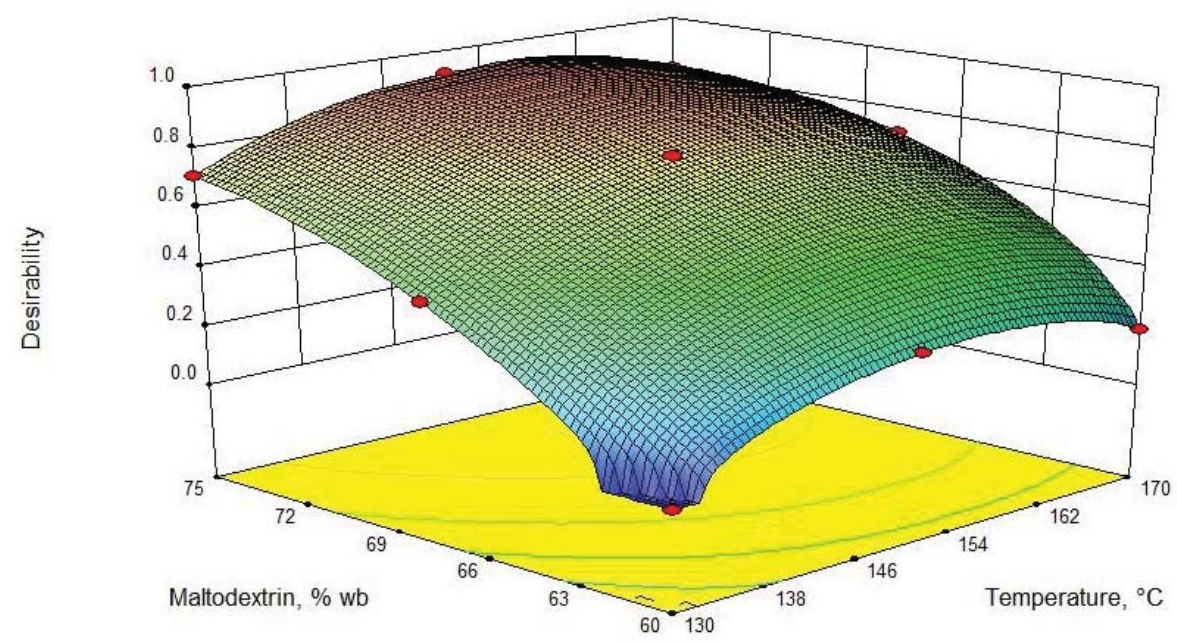

Fig. 1. Response surface plot for optimization of the spray-drying process for concentrated orange juice

Regarding the microstructure of the orange juice powder obtained with the optimized parameters, it was noted that the particles have a higher degree of uniformity regarding shape and good distribution (smooth and intact surfaces). The average particle size $\mathrm{D}_{43}$ was $10.0 \pm 0.7$ $\mu \mathrm{m}$, similar to the range from 10-100 $\mu \mathrm{m}$ commonly found for this technology (BufFo et al., 2002).

The addition of higher amounts of additive could drastically change the original sensory characteristics of the product. The sensory characteristic of the reconstituted powder obtained with the optimized parameters influenced the consumer perceptions of freshness and sweetness. Notably, the taste of the reconstituted powder was described as "low freshness" and "sweet" by some consumers. Nevertheless, the reconstituted powder reached $70 \%$ acceptance. Summarizing these results, the obtained orange juice powder is a promising material for food industry.

\section{Conclusions}

Inlet air temperature and maltodextrin content showed significant effect on all responses studied in the spray-drying process for the development of orange juice powder. Increasing temperature led to higher ascorbic acid retention, while this factor had negative effect on moisture content. The increase of maltodextrin content produced a rise in powder yield and 
ascorbic acid retention, although this factor had negative effect on moisture content, confirming its efficiency as a carrier agent. By response surface methodology, an optimum spray-drying process (inlet air temperature $155^{\circ} \mathrm{C}$, maltodextrin content $74 \% \mathrm{wb}$ ), under the parameters studied in this work, was estimated to produce orange juice powder with highly acceptable physical and chemical properties and with positive commercial implications.

\section{References}

AOAC (2006): Official methods of analysis, 18th ed., Association of Official Analytical Chemists, Gaithersburg, MD. Method 967.21

Buffo, R.A., Probst, K., Zehentbauer, G., Luo, Z. \& Reineccius, G.A. (2002): Effects of agglomeration on the properties of spray-dried encapsulated flavours. Flavour Frag. J., 17, 292-299.

Cesar, T.B., Aptekmann, N.P., Araujo, M.P., Vinagre, C.C. \& MaranhaO, R.C. (2010): Orange juice decreases lowdensity lipoprotein cholesterol in hypercholesterolemic subjects and improves lipid transfer to high-density lipoprotein in normal and hypercholesterolemic subjects. Nutr. Res., 30(10), 689-694.

Chegini, R.G. \& Ghobadian, B. (2005): Effect of spray-drying conditions on physical properties of orange juice powder. Drying Technol., 23, 657-668.

Chegini, R.G. \& Ghobadian, B. (2007): Spray dryer parameters for fruit juice drying. World J. Agric. Sci., 3, 230236

Chegini, R.G., Khazaei, J., Ghobadian, B. \& Goudarzi, A.M. (2008): Prediction of process and product parameters in an orange juice spray dryer using artificial neural networks. J. Food Eng., 84, 534-543.

Cuevas-Glory, L., Bringas-Lantigua, M., Sauri-Duch, E., Sosa-Moguel, O. \& Pino, J. (2017): Spray drying and process optimization of sour orange juice. Acta Alimentaria, 46, 17-26.

Fazaeli, M., Emam-Djomen, Z., Ashtari, A.K. \& Omid, M. (2012): Prediction of the physicochemical properties of spray-dried black mulberry (Morus nigra) juice using artificial neural networks. Food Bioprod. Process., 90, $667-675$.

Gharsallaoui, A., Roudaut, G., Voilley, C.O. \& Saurel, R. (2007): Applications of spray-drying in microencapsulation of food ingredients: An overview. Food Res. Int., 40, 1107-1121.

Goula, A.M. \& Adamopoulos, K.G. (2010): A new technique for spray drying orange juice concentrate. Innov. Food Sci. Emerg., 11, 342-351.

Islam, M.Z., Kitamura, Y., Yamano, Y. \& Kitamura, M. (2016): Effect of vacuum spray drying on the physicochemical properties, water sorption and glass transition phenomenon of orange juice powder. J. Food Eng., 169, 131140.

JAYA, S. \& DAS, H. (2004): Effect of maltodextrin, glycerol monostearate and tricalcium phosphate on vacuum dried mango powder properties. J. Food Eng., 63, 125-134.

Kaya, A., Aydin, O. \& Kolayli, S. (2010): Effect of different drying conditions on the vitamin C (ascorbic acid) content of Hayward kiwifruits (Actinidia deliciosa Planch). Food Bioprod. Process., 88, 165-173.

Krishnaiah, D., Nithyanandam, R. \& Sarbatly, R. (2014): A critical review on the spray drying of fruit extract: Effect of additives on physicochemical properties. Crit. Rev. Food Sci., 54, 449-473.

Mishra, P., Mishra, S. \& Mahanta, C.L. (2014): Effect of maltodextrin concentration and inlet temperature during spray drying on physicochemical and antioxidant properties of amla (Emblica officinalis) juice powder. Food Bioprod. Process., 92, 252-258.

Montgomery, D.C. (2013): Design and analysis of experiments, John Wiley \& Sons, New York. pp. $478-553$.

Moreira, G.E.G., De Azeredo, H.M.C., De Medeiros, M.F.D., De Brito, E.S. \& De Souza, A.C.R. (2010): Ascorbic acid and anthocyanin retention during spray drying of acerola pomace extract. J. Food Process. Pres., 34, 915-925.

Movahned, M.K. \& Mohebi, M. (2016): Spray drying and process optimization of carrot-celery juice. J. Food Process. Pres., 40, 212-225.

Murugesan, R. \& Orsat, V. (2012): Spray drying for the production of nutraceutical ingredients - A review. Food Bioprocess. Technol., 5, 3-14.

Muzaffar, K., NAYiK, G.A. \& Kumar, P. (2015): Stickiness problem associated with spray drying of sugar and acid rich foods: A mini review. J. Nutr. Food Sci., S12, 003 
O’Neil, C.E., Nicklas, T.A., Rampersaud, G.C. \& Fulgoni, V.L. (2011): One hundred percent orange juice consumption is associated with better diet quality, improved nutrient adequacy, and no increased risk for overweight/obesity in children. Nutr. Res., 31(9), 673-682.

Patil, V., Kumar, A. \& Singh, R. (2014): Optimization of the spray-drying process for developing guava powder using response surface methodology. Powder Technol., 253, 230-236.

Phisut, N. (2012): Spray drying technique of fruit juice powder: Some factors influencing the properties of product. IFRJ, 19, 1297-1306.

RaO, R.H.G. \& GuPTA, P.M. (2002): Development of spray dried orange juice blended skim milk powder. Lait, 82, 523-529.

Shrestha, A.K., Ua-Arak, T., Aghikari, B. \& Bhandari, B. (2007): Glass transition behavior of spray dried orange juice powder measured by differential scanning calorimetry (DSC) and thermal mechanical compression test (TMCT). Int. J. Food Prop., 10, 661-673.

Singh, V.K., Mandhyan, B.L., Pandey, S. \& Singh, R.B. (2013): Process development for spray drying of ber (Ziziphus jujube L.) juice. Am. J. Food Technol., 8(3), 183-191.

TAN, L.W., TAIP, F.S., IBRAHIM, M.N. \& KAMIL, R. (2011): Empirical modeling and control for spray drying of orange juice powder. 4th International Conference on Modeling, Simulation and Applied Optimization, ICMSAO 2011; Kuala Lumpur; Malaysia; 19-21 April 2011.

Verma, A. \& Singh, S.V. (2013): Spray drying of fruit and vegetable juices - A review. Crit. Rev. Food Sci., 55(5), 701-709.

Wang, S., Konkol, E. \& Langrish, T.A.G. (2011): Spray drying of fruit juice using proteins as additives. Dry. Technol., 29, 1868-1875. 